\title{
Legitimidad y democracia: dos décadas de un debate inconcluso
}

\author{
FRANCISCO COLOM GONZALEZ
}

Instituto de Filosofia, CSIC

Es costumbre en la industria cultural acuñar escuetos calificativos con los que se identifica a posterioni, de forma intencionadamente sencilla, periodos enteros de producción artística e intelectual. Algo similar viene ocurriendo en el terreno de la historia social y política. Así como la «silenciosa" década de los cincuenta se vio sucedida por los «alegres y prodigiosos» años sesenta, probablemente el decenio que ahora despedimos sea catalogado en el futuro como una auténtica época de "restauración" si se contrasta con los cambios y la tensión política que marcaron sus años previos. Ha sido ésta una restauración que se reflejó en el ámbito internacional con el inicio de la era Reagan y en la vida social con la entrada masiva de aires igualmente restauradores, que no tardaron en afectar a una serie de valores culturales, sociales y económicos, como los de jerarquía social, mercado, familia, religión, etc., que habían sufrido una considerable erosión en las sociedades occidentales durante la anterior década. Finalmente, la nueva distensión internacional, las revoluciones democrálicas del pasado año en el Este (interpretables, también en algunos casos, como «restauraciones democráticasn) y la reconfiguración de fuerzas en Centroeuropa parcecn marcar la pauta de lo que quizá constituya el paradigma político del decenio que ahora inauguramos. En cualquier caso, lo cierto es que el carácter del debate sobre legitimación ha corrido una suerte paralela a lo que cabria denominar el «tono po- lítico vital" de las sociedades democráticas durante este largo periodo.

Los años cincuenta, insertos en el entorno de la guerra fría, y caracterizados por una pacificación social vinculada al incipiente despegue de una *cultura del bienestar» que ponía fin a las estrecheces de la larga y penosa posguerra, se despidieron intelectualmente con los augurios de un final de época en un estilo que parece haber creado moldes para el posterior pensamiento social conservador. Me refiero a la tesis del «final de las ideologías", cuya versión actualizada parece corresponderse con el "final de la historia» recientemente pronosticado por Francis Fukuyama, si bien nos encontrariamos ahora frente a un supuesto ocaso histórico auspiciado por el triunfo de una única y última "utopía ideológica», a saber, la liberal en su acepción restringida.

Fuertemente influidos por el funcionalismo parsoniano dominante en la sociología de la época, una serie de autores americanos y europeos encabezados por Edward Shils, Seymour $M$. Lipset, Daniel Bell y Raymond Aron interpretaron en esos años la participación política de las clases trabajadoras en los sistemas parlamentarios, el creciente bienestar procurado por la transformación del capitalismo, y la «ruptura fina» de los intelectuales de izquierda con el stalinismo, como el signo de una progresiva integración social que no dejaba ya lugar para las idcologías humanistas del siglo XIX. Las sociedades occidentales de la era postideológica, una vez resueltos sus 
antiguos problemas sociales, se caracterizaron por descansar sobre un consenso normativo y por la aproximación pragmática a los problemas residuales derivados de la redistribucción de recursos. Los conflictos ideológicos se vieron sustituidos, pues, por una administracion consensuada de rasgos fundamentalmente tecnocráticos; un diagnóstico, por cierto, que pronto encontró interesados seguidores en nuestro patio nacional, donde no se dudó en vislumbrar un crepúsculo ideológico similar para un país al que dudosamente cabia atribuir los calificativos de «industrial», «avanzado» $\mathrm{y}$, mucho menos, de «democrático», sin una notable dosis de cinismo. $\mathrm{Ni}$ que decir tiene que los conflictos raciales norteamericanos de los años sesenta y la polarización de actitudes frente a la guera de Vietnam, así como las revueltas estudiantiles y el resurgimiento en la década de los setenta de los conflictos industriales en Europa, aportaron una suficiente refutación empírica de la citada tesis. Ciertamente, más que su ocaso definitivo, el enunciado del «final de las ideologías " constituyó la ideología propia del consenso del bienestar. Ante semejante evolución histórica, Lipset y Bell se vieron obligados con el tiempo a matizar y relativizar sus anteriores afirmaciones, ${ }^{1}$ reconduciéndolas en el caso del último hacia su teoría de la sociedad postindustrial.

El surgimiento del debate sobre la legitimación política, tal y como lo conocemos en su forma actual, tuvo lugar en el curso de ese progresivo caldeamiento de la esfera pública de las sociedades occidentales durante los altimos años sesenta, unas sociedades que, en palabras de Bell, hacía tiempo que habian perdido sus «amarras culturales ${ }_{2}^{2}$ Por ello no resulta sorprendente que el contexto inmediato del que partió el citado debate cayese fue- ra del ámbito académico, en donde podía haberse preservado la tradición inaugurada por Weber con su sociología de la dominación. La discusión se fraguó más bien en el seno de la reanimada cultura marxista de posguerra, liderada al final de esa década por el estructuralismo francés y por la redescubierta steoría crítica» francfortiana. Más concretamente, fue la reformulación althusseriana del concepto gramsciano de "hegemonía" la clave que indirectamente abrio las puertas al tratamiento de la legitimación.

Gramsci consideró que la perpetuación de la hegemonía ideológica de las clases dominantes era un producto de la sociedad civil y de las instituciones "privadas" que la cimentaban (Iglesia, sindicatos, escuelas...), frente a la cual los elementos represores del Estado aportaban el equilibrio necesario entre consenso y coerción. Althusser, en un giro conceptual, hizo de esas instituciones civiles de reproducción hegemónica instancias ideológicas que quedaban incluidas en el conjunto de los «aparatos del Estado», insertos a su vez en el esquema causal de una "sobredeterminación" económica. Con ello, el componente de contingencia que Gramsci concedía al conflicto por la hegemonía en la sociedad civil pasó a integrarse con Althusser en el planteamiento marxista más convencional de la ideología dominante.

Apoyado en las categorías del estructuralismo althusseriano, Nicos Poulantzas abordó en 1968 un estudio del sistema político de las sociedades capitalistas en donde analizaba el concepto de "legitimidad" desde la citada clave de la ideología dominante. ${ }^{3}$ Un año más tarde, Ralph Miliband se replanteaba igualmente la pregunta gramsciana por la secular hegemonía de las clases poseedoras, en un contexto institucional caracterizado por la compe- 
tencia política abierta; pero abordaba sin embargo la cuestión desde la perspectiva de una teoría pluralista de las elites. ${ }^{4}$ La clave de la legitimación politica del sistema capitalista residía para él en un proceso de «adoctrinamiento masivo" dirigido a la "fabricación del consentimiento». La legitimidad política carecía en este contexto, pues, de toda virtualidad normativa y debía ser entendida sociológicamente como un "proceso de legitimación " desarrollado fundamentalmente por las elites de la sociedad civil, pero en donde el Estado, al igual que en las demás áreas, estaba cobrando un creciente protagonismo. Para confirmar esta tesis, Miliband pasaba revista a toda una serie de instancias legitimantes tales como los partidos políticos, las iglesias, la prensa, las instituciones educativas, ctc.

Las perspectivas de ambos autores acabaron finalmente enzarzadas en un debate cruzado de artículos en la New Left Review en torno a las claves interpretativas del Estado capitalista. Esta fue, ante todo, una discusión metodológica en donde la cuestión de la legitimación política quedó relegada a un lugar secundario, pero tuvo el efecto de centrar durante los años posteriores la atención teórica de la izquierda sobre un ámbito tradicionalmente relegado en sus reflexiones políticas y que, sin embargo, habia sufrido una transformación radical a lo largo del siglo: la acción del nuevo Estado intervencionista.

Fue, sin embargo, otra derivación del funcionalismo parsoniano, más concretamente la teoría de sistemas de Niklas Luhmann, la que articuló la discusión sociológica en torno al fenómeno de la legitimación política. ${ }^{5}$ Conviene advertir aquí que este debate no siempre estuvo a salvo de imprecisiones terminologicas y que no giró tanto sobre el concepto de "legitimidad» propiamente dicho, esto es, sobre un atributo normativo del dominio político, cuanto sobre el concepto de slegitimación", por el que se entiende un proceso sociológico que genera lealtades políticas y estabilidad social.

La categoría de "dominio legítimo" data de la Edad Media, donde su contexto jurídico-político estaba dado por el circunstancial derrocamiento violento del soberano y por la defensa frente a la usurpación y la tiranía. Su significado específico on la sociedad burguesa se deriva, sin embargo, de las teorias jurídicas que cuajaron en la lucha contra el absolutismo, y más concretamente de la contraposición del «principio de legitimidad» dinástica efectuada por la restauración francesa de 1814 frente a la legalidad todavía vigente del código napoleónico. ${ }^{6}$ Tan sólo con el espacio de libertad ganado para la sociedad civil por la burguesía revolucionaria del siglo xvII resultó posible concebir en la categoria de la legitimidad una dimensión subjetiva de racionalidad como la recogida por Weber para la sociedad moderna, en su conocida tipologia de las formas de dominación. No obstante, el proceso histórico de positivación del Derecho da fe de la pronta inviabilidad que esta categoría mostró como criterio normativo para la fundamentación jurídica. Consiguientemente, el principio de legitimidad quedó formalmente vinculado al principio de legalidad entendido como criterio procedimental. La legitimidad de una ley en sentido jurídico positivo no depende ya, pues, de su sanción por un determinado orden cosmológico ni de su coincidencia con un criterio subjetivo de «justicia», sino de su correcta promulgación a partir de las normas o valores recogidos constitucionalmente.

Luhmann partió en su obra, sin embargo, de una perspectiva de corte funcional: la evidencia de que todo régi- 
men de dominación se asienta sobre alguna fómula combinatoria de coerción y consenso, recursos ambos escasos en un sistema político. Entendía por ello la legitimidad como da disposición generalizada a aceptar decisiones de un contenido todavía indeterminado dentro de un cierto margen de tolerancias. Frente a tal predisposición amorfa, la duda del sociólogo residía en si ésta es fruto de una sencilla motivación psicológica (la participación democrática, por ejemplo) o de una serie de mecanismos sociales que nivelan motivaciones de índole muy heterogénea. En su concepto de legitimación procedimental Luhmann optó por esta segunda variante. En las complejas sociedades modernas, el procedimentalismo legal contaría con un reconocimiento generalizado para sus premisas independientemente de la capacidad de satisfacción de las decisiones particulares. La legitimidad estaría vinculada, pues, a un proceso motivado de aprendizaje por parte de los individuos. En el curso de ese proceso, la aceptación de las decisiones vinculantes quedaria acoplada al reconocimiento de la competencia procedimental de las instancias decisorias. ${ }^{8}$

Los procedimientos legales, por su parte, globalmente considerados, no serían sino principios de acción generadores de decisiones que preservarian la identidad de un sistema social, delimitando y reduciendo su complejidad interna frente a la contingencia del entorno extrasistémico. Prescindiendo de la jerga propia de la teoria de sistemas puede decirse que los procedimentalismos legales constituyen, en definitiva, los mecanismos de adaptación y preservación de una estructura social cohesionada.

Los planteamientos iuhmannianos encontraron una pronta réplica en las obras de Claus Offe y Jürgen Haber- mas. ${ }^{9}$ Al primero de ellos se debe el esquema que presenta el problema de la legitimación política como un elemento permanente de crisis en las socicdades capitalistas. Habermas, por su parte, insertaria ese esquema en una "reconstrucción' del marxismo que pretendia dar cuenta de la evolución histórica de los criterios de validez normativa así como de los modos de socialización moral y política de los sujetos.

La intención que movía a Offe en su obra puede decirse que era la de realizar una lectura de Weber a contrapelo. Se trataba de reelaborar una teoria del capitalismo avanzado que recogiese las "disfuncionalidades" o efectos colaterales adversos para la integridad del sistema, generados precisamente por la intervención del Estado en sus funciones de regulación social y económica. El núcleo de esa disfuncionalidad sistémica no se encontraria directamente en la esfera de la producción, tal y como han mantenido tradicionalmente los teóricos marxistas de las crisis. Se hallaría más bien emplazado en la propia dinámica del sistema político-administrativo, cuya acción contaría con las condiciones capitalistas de reproducción como premisas incuestionadas.

Para Offe, resumidamente, las sociedades del capitalismo tardio se caracterizarían por un cierto proceso de "desmercantilización" (Dekommodifizienung) global expresado en la progresiva organización administrativa de los mercados, en los programas sociales destinados a amortiguar los riesgos del trabajo asalariado y en la politización de unos ámbitos de reproducción de la fuerza de trabajo, como familia y cducación, tradicionalmente "vírgenes" a la acción burocrática. Así como en el capitalismo liberal la fuente de equilibrio de la organización del trabajo 
consistía exclusivamente en el reconocimiento de la "equivalencia» de los intercambios de mercado recogida por la categoría jurídica del contrato, las nuevas funciones administrativas del Estado, destinadas a lograr ese mismo equilibrio en nuestras sociedades estarian sometidas a una necesaria «legitimación». Se trata, en definitiva, del hecho de que "mientras los datos del mercado tan sólo necesitan ser registrados, las decisiones burocráticas, por el contrario, precisan una fundamentación». ${ }^{10}$ Sin embargo Offe, oponiéndose a Luhmann, tan sólo concedía capacidad autónoma de legitimación a las reglas procedimentales alli donde éstas no fuesen susceptibles de ser adscritas a un interés concreto o cuando se aplicasen sobre constelaciones de problemas escasamente conflictivos.

Jürgen Habermas, por su parte, complementaría esta tesis enfatizando el carácter endémico de los problemas legitimatorios en las sociedades de capitalismo avanzado, como resultado de la irreversible evolución histórica de los criterios de justilicación moral hacia cánones universalistas. Teniendo en cuenta que klas motivaciones de los sujetos no se forman con independencia de la fuerza justificativa de las legitimaciones (...), o lo que es igual, con independencia del potencial de las razones que se puedan movilizar para aquellas"," el problema no consistiria ya en cómo ocultar las vinculaciones funcionales entre la actividad del Estado y la economía capitalista, sino en presentar las prestaciones de esta última como la mejor forma de satisfacer los intereses generales. Las legitimaciones servirian, pues, para mostrar por qué las instituciones existentes son las más adecuadas para realizar los valores constitutivos de la identidad social. La razón ûltima de los crónicos déficits legitimatorios de las sociedades de capitalismo avanzado residiría en la tensión que arraiga originariamente en su formula constitutiva. Esta pretende conciliar una estructura social de clases con el libre juego de la inversión de capitales y con los principios políticos de la democracia, una constelación què ha encontrado su respuesta histórica en la inestable y contradictoria combinación de Estado de bienestar y democracia parlamentaria de masas.

No es preciso señalar que las obras de Luhmann, Offe y Habermas fueron escritas antes del largo periodo de recesión económica iniciado con la crisis energética de 1973. Inversamente a las esperanzas abrigadas por el marxismo del siglo XIX, quien, en virtud de sus supuestos efectos revolucionarios, veía en las crisis económicas su mejor aliado político, la agudización de la crisis en los países occidentales trajo como consecuencia a largo plazo un profundo disciplinamiento social, y el imparable ascenso de las políticas económicas de corte neoliberal desarrolladas, con diversos matices, por gobiernos conservadores y socialdemócratas. En este contexto, el debate sobre los problemas de legitimación en las sociedades, que un día Galbraith había tildado de opulentas, muy pronto se tornó en discusión acerca de la sobrecarga de exigencias a que se veía sometido el Estado y de los limitados recursos con que éste contaba para operar. Este síndrome quedó efímeramente acuñado con el denominador común de la «ingobernabilidad" a que supuestamente habian llegado los modelos del bienestar, y digo efímeramente porque el debate desapareció de la escena académica tan pronto como una serie de gobiernos conservadores comenzaron a aplicar la estrategia de urepliegue» del Estado. ${ }^{12}$ A partir de ahi la discusión se centró en la búsqueda, desafortunada hasta el momento, de posibles alter- 
nativas a las políticas de bienestar social, sobre el posible retorno a las dimensiones mínimas del Estado liberal, con la consiguiente descarga de presiones legitimatorias, y sobre los márgenes tolerables de desigualdad social, unos márgenes reflejados en la noción, tan popularizada últimamente, de la «sociedad de los dos tercios".

Las obras de Habermas y Offe sobre los procesos de legitimación terminaron por constituinse en centro de referencia, directa o indirecta, de la enorme avalancha de estudios que sobre dicho tema sobrevino con posterioridad y que, con menor empuje, continúa hasta nuestros días. Las distintas y múltiples direcciones adoptadas por esta oleada me impide ofrecer aquí una relación pormenorizada de sus contenidos. En las líneas que restan me limitaré, pues, a describir someramente los rasgos generales de las principales comientes que han cuajado sobre dicho tema durante los últimos años.

Por una parte, este debate ha contribuido al surgimiento de un campo de análisis en el seno de la politología comparada que atiende particularmente a las fórmulas y modelos concretos de legitimación de cada sistema político. En esta línea, algunos análisis han ampliado y afinado los diagnósticos de Habermas y Offe sobre la dinámica política del capitalismo. ${ }^{13}$ Muchos otros, sin embargo, han extendido la competencia de sus intereses a los mecanismos legitimatorios del denominado "socialismo real s y de los regímenes surgidos de los procesos de descolonización. ${ }^{14}$ Curiosamente, Seymour M. Lipset, uno de los adalides del eclipse ideológico en los años cincuenta, terminó por incorporarse en 1983 a esta nueva corriente con un estudio de los ciclos de estabilidad legitimatoria en la sociedad norteamericana, para la que, por cierto, auguraba en vísperas del triunfo de Ronald Reagan, una profunda pérdida de confianza de no resurgir un fuerte liderazgo político. 15

Una segunda derivación de este debate ha encontrado su centro de gravedad en el renacer experimentado por la filosofía política. Así, la pregunta sociológica por las formas externas de justificación de las estructuras de dominación social y política ha terminado por reavivar la pregunta filosoficomoral por las condiciones que debieran cumplir las anteriores para ser consideradas verdaderamente slegftimas ${ }^{16}$ Tal y como Habermas señaló al criticar el neutro formalismo weberiano, «la legitimidad significa el hecho del merecimiento de reconocimiento por parte de un orden político (...); la legitimidad constituye una pretension de validez discutible de cuyo reconocimiento fáctico depende la estabilidad de un orden de dominación". ${ }^{17}$

El interés habermasiano por replantear críticamente la fundamentación normativa de los sistemas democráticos parlamentarios encontró, por últímo, un pronto acomodo en el debate moral que dividió a la opinión pública alemana en torno a la desobediencia civil con motivo del despliegue de los «euromisiles» a comicnzos de los años ochenta. ${ }^{18}$ En el seno de esa discusión, Habermas expresó su convencimiento de que la desobediencia civil constituye la prueba más fehaciente de la madurez alcanzada por una cultura política democrática. Esa desobediencia moralmente molivada representaría el guardián último de la legitimidad del Estado democrático de derecho, una legitimidad no mensurable sin mayores consideraciones a partir del cálculo exclusivamente procedimental de la regla parlamentaria de mayorias. En este mismo sentido, Offe y otros autores recordaron las aporías y ambigüedades que comportan los métodos puramente 
demoscópicos de configuración de la voluntad, cuya legitimidad moral resulta especialmente dudosa cuando atañen a decisiones cargadas de una irreversible trascendencia futura. Abogaron, por ello, en favor de la limitación del principio de mayorías mediante el sometimiento de los criterios y condiciones de su aplicación a una decisión a su vez mayoritaria. ${ }^{19}$

También en nuestro país el debate sobre la vinculatoriedad de las decisiones jurídicas encontró cierta resonancia en el seno de una reflexión ético-jurídica a tres bandas entre González Vicén, Elías Díaz y Javier Muguerza sobre el sentido de la sdesobediencia éticas. Este es un punto, sin embargo, en el que no me detendré por aparecer recogido con mayor detenimiento en otra nota del presente número.

Tras este recorrido, necesariamente breve y apresurado, por la historia del debate general sobre temas de legitimación, tan sólo restaría constatar lo lejos que aparentemente nos encontramos de un fin concebible para el mismo. $A$ buen seguro nos espera un in- minente aluvión de estudios sobre el colapso político de los países del Este europeo. A modo de colofón cabría, sin embargo, atribuirle al citado debate un sentido global de desarrollo. En efecto, la discusión iniciada hace ya más de dos décadas sobre la legitimación de los sistemas políticos capitalistas ha terminado por cuajar en un renovado interés filosófico por la posibilidad de fundamentar la legitimidad moral de todo orden de dominación, un interés que no puede dejar de ponderar las consecuencias éticas y politicas que de cada fórmula propuesta se desprenden para la acción humana. Así parcen también confirmarlo los últimos escritos de Habermas al respecto, donde prelende enraizar la legitimidad democrática del parlamentarismo en la naturaleza argumentativa de los procedimientos que sirven para la producción y aplicación de las normas legales. ${ }^{20} Y$ es que, en un universo político secularizado como el nuestro, la legitimidad posee un carácter procesal que la configura como tensión permanente y nunca como proyecto acabado.

\section{NOTAS}

1. Cfr. S.M. Lipset: El hombre polttico, Madrid, Tecnos, 1987, $3^{\text {a }}$ edición, p. 442 y D. Bell: Las contradicciones culturales del captatismo, Madrid, Alianza, 1977, p. 52.

2. En el decenio de 1950 el Estado benefactor y la economía mixta no constituian el tipo de objetivos que pudiera despertar la pasión de la inte. lectualidad. Además, aunque lass esperanzas polfticas radicales quedaron momentáneamente destruidas, la postura cultural básica siguió siendo la misma: el rechazo de los valores burgueses. En verdad, la continuidad del raclicalismo en esos años tue posible, no por la política, sino por la cultura", ibtd.

3. «Puede, en efecto, designarse por legitimidad de las estructuras y las instituciones polfticas su relación con la ideología dominante en una formación: más particularmente, la legitimidad recubre el impacto especificamente político de la ideologia dominante». Poder politico y clases 50 ciales en el Estado capitalista. Mexico, Siglo XXI, 1969 , p. 284 .

4. Crr. El Estado en la saciedad capitalista, México, Siglo XXI, 1970.

5. Cfr. N. Luhmann: Legitimation durch Verfah ren, Francfort, Suhrkamp, 1969.

6. Cfr. E. Diazi De la maldad estatal y la soberania popular, Madrid, Debate, 1984, p. 49 y ss.

7. Op. cit., p. 28.

8. "La legitimidad no reside en el reconocimiento 'voluntario', en una convicción personal que aporte justificaciones. Descansa, por el contrario, sobre un clima social que institucionaliza como evidencia el reconocimiento de las decisiones vinculantes y las contempla como resultado de la validez de una decisión oficial, no como consecuencia de una decisión personaln, op cit., p. 34 . 
9. Cfr. C. Offe: Strukturprobleme des kapitalistis chen Staates, Francfort, Suhrkamp, 1972 y J. Habermas: Problemas de legitimacion en el capitalismo tardfo, Buenos Aires, Amorrortu, 1975. El prolijo debate entre Habermas y Luhmann ha quedado parcialmente recogido en Theorie der GeseIlschaft oder Sozialtechnologie - Was leistet die Systemforschung?, Francfort, Suhrkamp, 1975.

10. C. Offe, op. cit., p. 50.

11. J. Habermas; op. cit., p. 249.

12. Sobre este tema cfr. fundamentalmente S. Brittan; "The Economic Contradictions of DeJuocracy", en British Joumal of Political Science, 5 (1975) pp. 129.159; R. Rose: "Overloaded Government en European Studies Newsletter (1975); W. Hemis, P. Graf Kielmannsegg y U. Matz (eds.): Regierbarkeit, Stutgart, Kohlhammer, 1977-1979 y C. Offe: "Unregierbarkeit». Zur Renaissance konservativer Krisentheorien, en J. Habermas (ed.): Stichworte zur 'Geistigen Situation der Zeit' (Bd. 1) Francfort, Suhrkamp, 1979, pp. 294-318.

13. Cfr., por ejemplo, A. Wolfe: Los limites de la legitimidad, Mexico, Siglo XXI, 1980.

14. Son de resaltar por su interés los que aparecen en las recopilaciones de D. Held (ed.): States \& Societies, Oxford, Basil Blackwell, 1983 y M. Dogan (ed.): Comparing pluralist Democracies. Strains on Legitimacy, Boulder, Westview Press, 1988. Destaca también, por su originalidad, la aplicacion de los esquemas de Habermas y offe a los países del Este europeo llevada a cabo por Andrew Arato. Cfr. ocritical Sociology and Authoritarian State Socialism*, en J.B. Thompson y D. Held (eds.): Habermas: Critical Debates. I.ondres, MacMillan, 1982, pp. 196-218.

15. Cfr. S.M. Lipset: Is there a Legitimacy Crisis?, en Micropolitics, Vol. 3, 1 (1983), pp. 1-37.

16. Al respecto $\mathrm{cfr}$. H. Kliemt: Filosofía del $\mathrm{Es}_{\mathrm{j}-}$ tado y criterios de legitimidad, Barcelona-Caracas, Alfa, 1979; W. Connolly (ed.): Legitimacy and the State, Oxford, Basil Blackwell, 1984; J, Keane: Public iffe and late capitalism, Cambridge, Cambridge Univ. Press, 1984 y D. Held: Models of Democracy, Cambridge, Polity Press, 1987.

17. J. Habermas op. cit., p. 243.

18. La bibliografía sobre desobediencia civil es muy abundante, pero son de destacar fundamentalmente las obras de R. Dworkin: Los derechos en serio, Barcelona, Aniel, 1984 y P. Glotz (ed.): Ziviler Ungehorsam ith Rechtsstaat, Francfort, Suhrkamp, 1983.

19. Cr. B. Guggenberger y C. Offe (eds.): An der Grenzen der Mehrheitsdemokratie, Opladen, Westdeutscher Verlag, 1984.

20. Cfr, J. Habermas: "How is Legitimacy Possible on the Basis of Legality? $y$ «On the Idea of the Rule of Law», en S.M, McMurrin (ed.): The Tanner Lectures on Human Valtues VIII, Salt Lake City-Cambridge, Univ, of Utah Press-Cambridge Univ. Press, 1988, pp. $219-249$ y $249-279$ respectivamente.

\title{
La recuperación analítica de la virtud clásica
}

\author{
ANDRÉS DE FRANCISCO y FERNANDO AGUIAR \\ Universidad Nacional de Educación a Distancia
}

Las lineas que siguen constituyen un comentario de la reciente e importante obra de Antoni Domènech, De la Ética a la Politica (De la razón erótica a la razón inerte), (Barcelona, Crítica, 1989). Ante un libro semejante, no sería extraño que un imaginario y despistado lector pensara que el aulor de este libro fuera más bien un equipo interdisciplinar de especialistas, pues en él se dan cita, como quien no quiere la cosa, el filósofo moral, el economista, el filólogo, el historiador de las ideas, el epistemólogo, el escritor experimentado... Pero no, el equipo se reduce a una sola persona. Nos encontramos, en efecto, ante una de las cabezas mejor amuebladas de nuestro paisaje intelectual, y no sólo del nuestro. Mas no se trata ya de meros conocimientos 